\title{
Colligo: aplicativo para dispositivos móveis para processos de gamificação em sala de aula
}

\author{
Alice M. Wiener ${ }^{1}$, Aline de Campos $^{1}$ \\ ${ }^{1}$ Escola de Tecnologia - Faculdade Senac Porto Alegre \\ Coronel Genuíno, 130 - Porto Alegre - RS - Brasil \\ \{alicewiener, alinedecampos\}@gmail.com
}

\begin{abstract}
The use of mobile devices opens up opportunities inside the classroom. These devices can become a motivation and collaboration element among students and teachers. They also increase the possibility of using techniques like gamification, which is the use of elements and mechanisms of games in different contexts. This paper aims to present the application Colligo and analyze through experimenting the possibilities of using this resource in the classroom. With this app, teachers can use quizzes, ranking, cards and badges in their classes, therefore interacting more with students, monitoring and taking decisions based on data, recognizing competences and stimulating the participation.
\end{abstract}

Resumo. $O$ uso de dispositivos móveis abre oportunidades em sala de aula, podendo se tornar elemento de motivação e colaboração para alunos e professores. Esse contexto aumenta a possibilidade do uso de técnicas como a gamificação, que consiste na utilização de elementos e mecânicas de jogos em diferentes contextos. Este trabalho apresenta o aplicativo Colligo e analisa as possibilidades de aplicação em sala de aula através de experimentações. Com o aplicativo, o professor pode criar questionários, gerar ranqueamento, trabalhar com conquistas de cartas e emblemas em suas aulas, podendo, assim, aumentar a interatividade com os alunos, monitorar e tomar decisões baseadas em dados, reconhecer competências e estimular a participação.

\section{Mobile learning e gamificação: novas possibilidades no ensino}

Uma das grandes discussões no âmbito da educação é o uso de celulares e tablets em sala de aula. Para alguns professores, essa tecnologia faz com que o aluno perca o foco das atividades e veem a inclusão desses aparelhos como um obstáculo no aprendizado. Outros, no entanto, percebem que essa é uma oportunidade para modificar a forma de interação com o conhecimento e também a interação em sala de aula, tanto aluno e professor, como alunos entre si.

A aprendizagem móvel, também chamada de Mobile Learning ou M-Learning, é definida pela Organização das Nações Unidas para a Educação, a Ciência e a Cultura (UNESCO) como o ensino que envolve o uso de aparelhos digitais e portáteis. Esse aprendizado permite que o conhecimento seja encontrado de forma ubíqua, ou seja, não apenas na sala de aula, com um professor, mas a qualquer hora e em qualquer lugar. Além disso, esse tipo de interface "abrange esforços em apoio a metas educacionais amplas, como a administração eficaz de sistemas escolares e a melhor comunicação entre escolas e famílias". [UNESCO, 2014, p. 06]. 
Ao longo dos anos esse cenário vem se desenvolvendo em conjunto com a popularização do acesso aos dispositivos móveis e a conexão com internet, fazendo com que a área educacional possa encontrar formas de usar esse contexto a seu favor. $\mathrm{O}$ grande desafio apresentado é a necessidade de elaborar estratégias pedagógicas que possam fazer uso do potencial dos dispositivos móveis sem perder o foco nos objetivos didáticos e educacionais [Moura, 2010, apud Chisholm, 2005].

A presença desses dispositivos aumenta a possibilidade do uso de técnicas como a gamificação, que, segundo Domínguez et al. (2013), é a utilização "de elementos e mecânicas de jogos, em um contexto que não seja de jogo". Ou seja, não se faz necessário que seja um jogo propriamente dito, mas que use mecanismos encontrados em jogos, como regras, premiações, pontuações, ranking e que estimule nos participantes aspectos de motivação e engajamento que frequentemente os jogos despertam.

Segundo Zichermann e Cunningham (2011), as pessoas jogam para obter o domínio de determinado assunto, para se entreter ou para socializar. Um dos grandes desafios da gamificação em sala de aula é fazer com que os jogos potencializem o aprendizado e não fiquem restritos a entretenimento. Ainda segundo os autores, é possível desenvolver a motivação extrínseca, ou seja, aquela que se inicia da vontade do sujeito de obter uma recompensa externa, através do ranking e premiação, por exemplo. No entanto, é necessário que esse método também desenvolva a motivação intrínseca, que é originária da curiosidade do sujeito. Essa última é mais difícil de ser alcançada, mas, com o tempo, a metodologia pode auxiliar os estudantes a se tornarem automotivados.

Sendo assim, o uso de processos semelhantes aos dos jogos, faz com que as práticas pedagógicas se aproximem da "linguagem a qual os indivíduos inseridos na cultura digital estão mais acostumados e, como resultado, conseguem alcançar essas metas de forma aparentemente mais eficiente e agradável" [Alves, Minho e Diniz, 2014].

\section{Análise de soluções existentes para mobile learning}

Percebe-se que a gamificação tem sido amplamente aplicada na concepção e desenvolvimento de aplicativos para dispositivos móveis. Entretanto, estes estão mais centrados em entretenimento, utilidades públicas e sistemas de avaliação de serviços e estabelecimentos como, por exemplo, Waze, Foursquare e Swarm. Algumas iniciativas famosas estão associadas a um contexto de aprendizagem, como por exemplo o aplicativo Duolingo, entretanto este não é aplicado em um contexto de sala de aula.

Ainda que poucas, existem algumas aplicações no mercado atual para uso no ambiente educacional. $\mathrm{O}$ uso dessas aplicações em sala de aula podem ter diversos benefícios, como permitir que o professor analise o aproveitamento das aulas. Uma aplicação que permite essa avaliação é o Nearpod, onde o professor pode criar e compartilhar conteúdo e atividades com seus alunos e verificar as respostas das atividades em tempo real, de forma que possa fazer uma avaliação contínua. Além disso, a aplicação permite que os alunos acessem o conteúdo disponibilizado fora de sala de aula, expandindo o ambiente de aprendizado [Nearpod, 2017].

Há também aplicativos que permitem que essa mesma avaliação contínua seja realizada utilizando outras metodologias de aprendizagem. Kahoot é uma aplicação que 
VI Congresso Brasileiro de Informática na Educação (CBIE 2017)

Anais do XXVIII Simpósio Brasileiro de Informática na Educação (SBIE 2017)

permite que o professor lance perguntas para a turma. Quando o tempo da pergunta termina, os alunos podem visualizar o número de alunos que escolheu cada opção de resposta e o ranking de pontos. Os alunos que responderem corretamente e mais rápido, receberão mais pontos. Dessa forma, o professor pode utilizar técnicas de gamificação para estimular a aprendizagem e avaliar a aprendizado da turma [Kahoot, 2017].

Complementando o projeto SMILE da Universidade de Stanford, que utiliza a abordagem de aprendizagem baseada em questionamentos [Seol et al., 2011], a proposta de França e Reategui (2013), SMILEBR, faz uso de técnicas de gamificação com o objetivo de aumentar a motivação e engajamento dos alunos. Através do aplicativo, os professores podem gerenciar temáticas, instigando os alunos a elaborarem questões sobre os assuntos. Essas perguntas podem ser respondidas e avaliadas por outros alunos. As respostas e avaliações geram pontos, que desbloqueiam novos recursos e geram um ranking dos alunos, no qual, segundo os autores, o objetivo "não é colocar em evidência o aluno que mostrou mais conhecimento em determinada área, mas valorizá-los pela sua participação, contribuição e engajamento no processo de construção de conhecimento."

Acredita-se que essas três soluções apresentam aspectos a melhorar no sentido de oferecerem apenas uma forma de utilização dos aspectos de gamificação, não permitindo assim que professores façam uma adaptação dos mecanismos disponíveis para cada grupo de alunos. É importante que os professores tenham o controle dos mecanismos já que é a partir da sua análise da turma que eles poderão moldar a abordagem pedagógica utilizada.

\section{Concepção de um aplicativo para mobile learning com gamificação}

Tendo em vista o potencial dos processos de gamificação em aplicativos educacionais e a pouca expressão desta integração atualmente, foi concebido o Colligo com o objetivo de estimular processos interativos entre professores e alunos através da gamificação e auxiliar no processo educacional. A primeira versão foi desenvolvida para dispositivos iOS e em sua concepção procurou-se estabelecer funcionalidades relevantes e fundamentadas em paradigmas educacionais, bem como apresentação visual e usabilidade atrativas a diversos públicos.

Em sua tese de doutorado, Moura (2010) faz um levantamento das perspectivas teóricas educacionais mais expressivas que podem ser associadas com as diversas possibilidades advindas do uso de dispositivos móveis na educação, entre elas: visões comportamentais, construtivistas, socioculturais, humanistas e de apoio ao ensino. Sendo assim, não se pode dissociar a elaboração ou utilização de recursos tecnológicos para dispositivos móveis dos objetivos educacionais. Para tanto, buscando atender demandas identificadas no mercado de aplicações móveis educacionais, bem como zelar pelas questões pedagógicas inerentes a esse tipo de projeto, o processo de concepção do Colligo foi centrado no estudo de perspectivas teóricas que pudessem auxiliar na modelagem de funcionalidades.

Indo ao encontro dos aspectos comportamentais, que levam em consideração a relação estímulo-resposta, acredita-se que uma funcionalidade capaz de instigar os alunos a reflexão de seu entendimento dos conteúdos é o questionário. Essa seção do aplicativo pode ser usada em sala de aula pela turma, e o professor pode realizar análise e feedback em tempo real. Além dessa funcionalidade, mostra-se importante desenvolver um espaço onde os professores podem enviar arquivos como material 
complementar para estudo por parte dos alunos. De acordo com Moura (2010) no "paradigma behaviorista adequa-se o uso de dispositivos móveis para enviar materiais de aprendizagem (estímulo), obter respostas dos alunos ou fornecer feedback adequado (resposta)". Neste sentido a resposta apresentada pelo professor ou pelo sistema funciona como o reforço necessário ao desenvolvimento do aluno. Pensou-se ainda na disponibilização do questionário para "jogar", onde o aluno pode acessar e construir seu conhecimento em outros momentos que não em sala de aula.

Levando-se em consideração o desejo de inserir aspectos de gamificação, a função de emblemas, estimula o aluno a aprender mais para atingir o objetivo de realizar uma nova conquista. Além disso, no aplicativo, o professor pode disponibilizar cartas com benefícios para que os alunos possam utilizá-las mais tarde. Essa funcionalidade, além de motivar, procura despertar a autonomia no aluno. Sendo assim, estas funcionalidades podem ser fundamentadas nas teorias construtivistas, onde as simulações participativas podem ser um exemplo de implementação da tecnologia móvel [Naismith et al., 2004].

A partir do questionário e de pontos que podem ser oferecidos pelo professor ao aluno, elaborou-se a funcionalidade de ranqueamento, onde todos podem verificar seu posicionamento perante os demais colegas e isto pode estimular processos competitivos saudáveis e colaborativos. Além disso, as cartas e emblemas que são conquistadas podem causar impacto social positivo. Pensou-se também numa funcionalidade de solicitar ajuda ao professor, num paradigma voltado ao sociocultural, onde entende-se que a interação do sujeito com o meio é um processo de fora para dentro, numa lógica onde as atividades usando dispositivos móveis promovem a aprendizagem através da interação social [Moura, 2010].

Levando em consideração aspectos da perspectiva humanista, os elementos de gamificação adicionados estimulam o foco na autorrealização, na satisfação e no crescimento pessoal do aluno, onde os sentimentos e ações são integrados. As cartas igualmente estimulam esses sentimentos uma vez que são expressões de valorização das ações do aluno pelo professor. A possibilidade de solicitar ajuda ao professor através do aplicativo demonstra uma maior disponibilidade e proximidade do docente.

E, para além dos aspectos pedagógicos, o aplicativo ainda conta com importantes funcionalidades que são de apoio ao ensino como, por exemplo, criação e gestão de turmas, criação e gestão de questionários, controle de presença em aula, cronograma de aulas, envio de arquivos e avisos uma vez que para um bom fluxo dos processos depende-se do arranjo de coordenação tanto dos alunos, quanto dos recursos [Nas Smith et al., 2004].

Além disso, importante ressaltar o papel do professor nesse contexto. Através de configurações no aplicativo, o docente tem o controle para definir quais funcionalidades podem ser usadas em cada turma. Cabe a ele, analisar a turma e verificar quais funções se enquadram melhor para cada grupo de alunos, já que são diferentes e podem reagir de formas diferentes a cada estímulo.

\section{Funcionalidades do aplicativo Colligo e seus potenciais de aplicação}

Como em um ambiente escolar estão envolvidos muitos perfis, o projeto foi desenvolvido com o foco no professor e no aluno. $O$ usuário, após realizar sua autenticação ou registro, é levado para a sua lista de turmas, conforme interface a 
VI Congresso Brasileiro de Informática na Educação (CBIE 2017)

Anais do XXVIII Simpósio Brasileiro de Informática na Educação (SBIE 2017)

esquerda da figura 1. Quando o professor cria uma nova turma (figura 1 ao centro), além de definir cores e informações gerais, deve escolher quais funcionalidades gostaria que estivessem ativadas para essa turma. Essas opções são configuráveis para que professor possa definir o que gostaria de usar conforme a necessidades da turma. Após criada a turma, o professor ou aluno poderá acessá-la e visualizar suas informações, conforme figura 1 a direita.
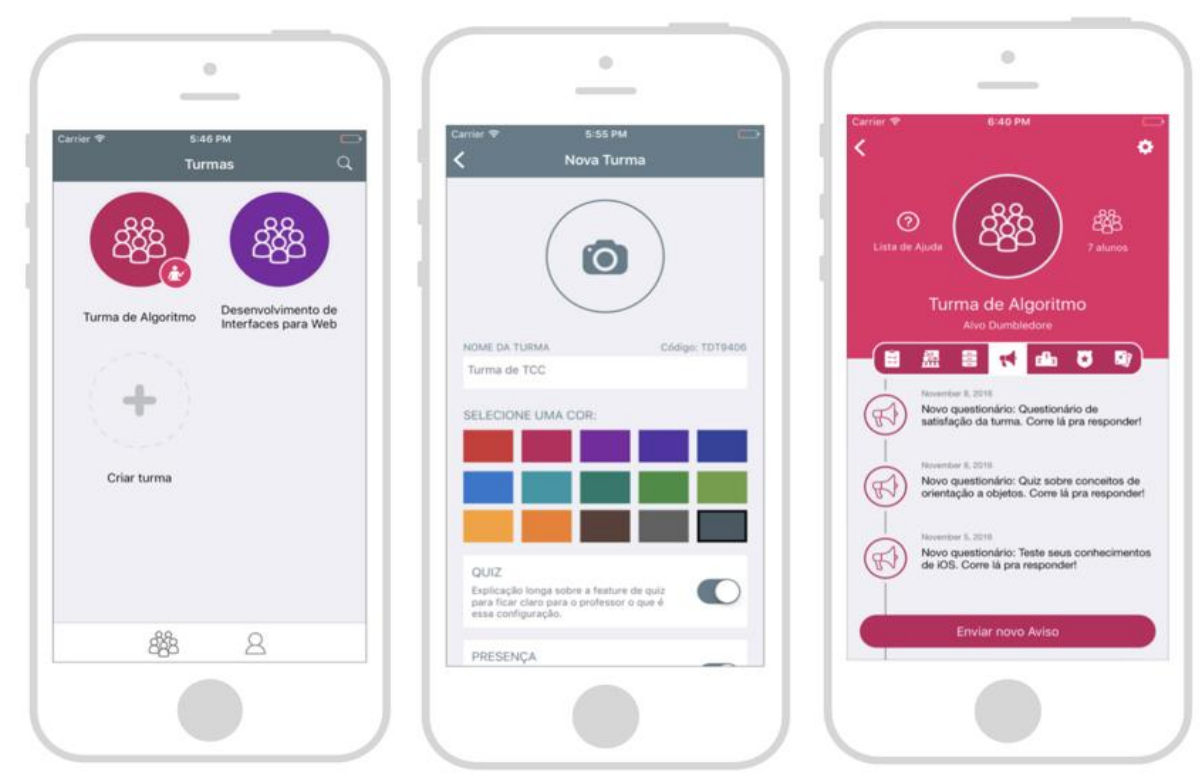

Figura 1. a) Interface para visualizar turmas (esquerda); b) criar novas turmas (centro); c) visualizar detalhes da turma (direita);

Se o professor habilitar a funcionalidade de questionários, é possível cadastrar questionários e enviar para a turma. Os questionários contém perguntas de múltipla escolha e, em cada pergunta, pode ser definida a resposta correta e a quantidade de pontos que o aluno receberá caso acerte. Além disso, o professor pode definir se a resposta correta deve ser mostrada ao aluno depois de respondida cada pergunta, ao finalizar o questionário ou se a respostas corretas não devem ser mostradas. Dessa forma, o professor tem liberdade para conduzir o processo educacional propiciado pelos questionários conforme sua necessidade.

A lista de questionários enviados para a turma pode ser visualizada pelos alunos e professores, conforme a primeira interface na figura 2. Os alunos responderão às perguntas (figura 2 ao centro a esquerda) e ao finalizar o questionário uma mensagem e um gif animado serão mostrado ao aluno (figura 2 ao centro a direita). Essa animação é personalizada para a pontuação que o aluno alcançou com o questionário respondido. Mesmo que o aluno não tenha conseguido uma boa pontuação, a animação deverá motivar o aluno a participar novamente. Enquanto a turma responde ao questionário, o professor pode visualizar o gráfico de respostas (figura 2 a esquerda), onde é mostrada a porcentagem de alunos que escolheram as alternativas. Além disso, o professor pode visualizar a lista de alunos que responderam e quais as alternativas eles escolheram. Dessa forma, o professor pode avaliar rapidamente o andamento da aula e visualizar quais assuntos necessitam ser revisados. O professor pode ainda disponibilizar esse mesmo questionário para jogar. Ou seja, os alunos podem respondê-lo mais de uma vez, 
VI Congresso Brasileiro de Informática na Educação (CBIE 2017)

Anais do XXVIII Simpósio Brasileiro de Informática na Educação (SBIE 2017)

podendo assim retomar seus conhecimentos em um determinado assunto fora da sala de aula.
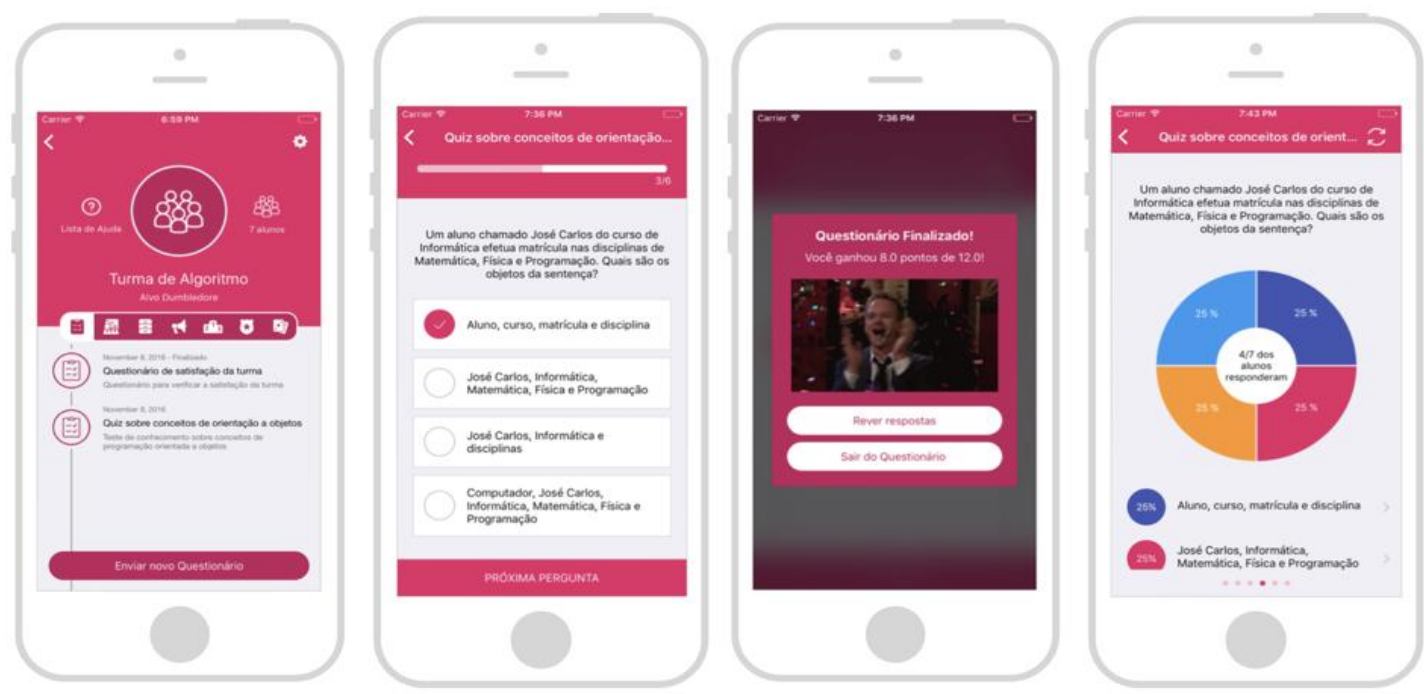

Figura 2. a) Interface para visualizar questionários (esquerda); b) responder questionário (centro a direita); c) finalização do questionário; d) visualizar resultados (centro a esquerda);

Como forma de ajudar na organização e centralização das informações da aula, o professor ainda pode escolher realizar a conferência de presença do aluno dentro do aplicativo. Nesse caso, precisa criar as aulas, podendo assim definir uma descrição dos conteúdos e estabelecer um cronograma. Essa informação também é disponibilizada para o aluno (figura 3 a esquerda). Além disso, no dia da aula o professor pode realizar a lista de presença manualmente ou pode ser auxiliado pela tecnologia iBeacon ${ }^{1}$. Com ela, o professor não precisará realizar a chamada. Quando o horário da aula iniciar, o aplicativo do professor enviará um sinal para os dispositivos próximos, realizando assim a presença do aluno, sem nem a necessidade do professor ou aluno abrir o aplicativo. Fazendo uso desta mesma tecnologia, quando o aluno estiver em sala de aula poderá solicitar ajuda ao professor através do aplicativo. O professor terá uma lista de alunos que fizeram a solicitação, podendo auxiliá-los organizadamente, uma vez que também é objetivo desse projeto aumentar a interatividade dos envolvidos nesse contexto.

No caso da funcionalidade de envio de arquivos (figura 3 ao centro), é possível que o professor envie arquivos do tipo PDF para a turma. Para isso, foi feita integração com o Google Drive para que o professor possa buscar os seus arquivos e enviá-los para as turma. Assim, o docente concentra os arquivos disponibilizados para a turma no aplicativo, facilitando o acesso.

Caso a funcionalidade de ranking seja configurada para a turma (figura 3 a direita), a posição dos alunos com relação aos pontos conquistados será mostrada para toda a turma. Dessa forma, o professor pode incentivar o estudo através da gamificação. Ainda há a possibilidade do professor dar pontos extras para os alunos por uma determinada atividade ou conquista. O ranking, portanto, é formado a partir do resultado dos questionários e dos pontos extras.

${ }^{1}$ iBeacon é uma tecnologia que utiliza Bluetooth Low Energy (BLE) e permite que um dispositivo 
VI Congresso Brasileiro de Informática na Educação (CBIE 2017)

Anais do XXVIII Simpósio Brasileiro de Informática na Educação (SBIE 2017)
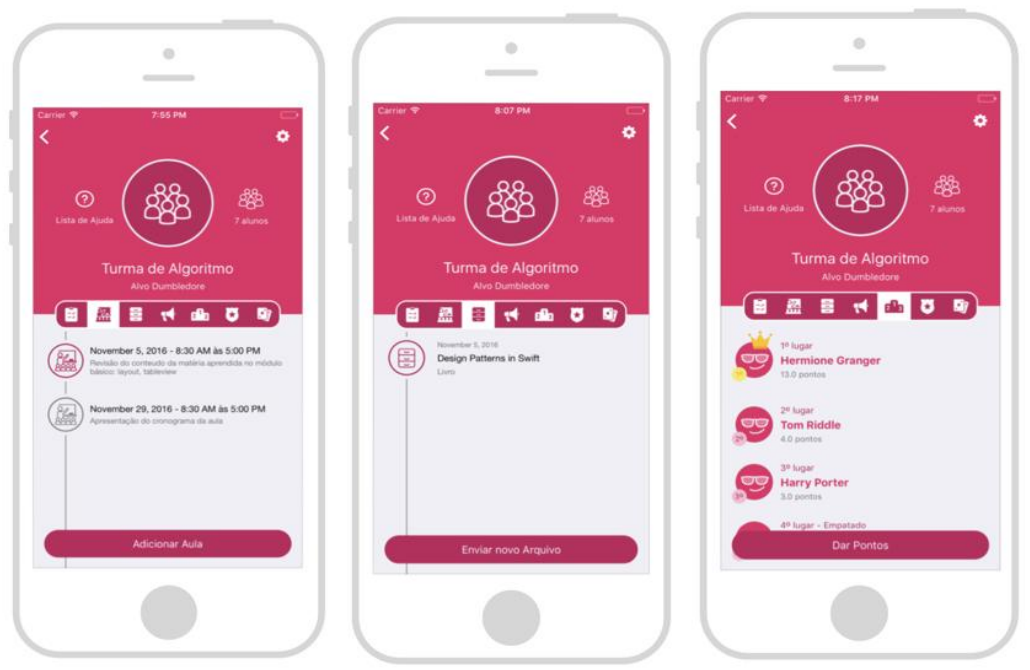

Figura 3. a) Interface para visualizar presenças (esquerda); b) visualizar arquivos (centro); c) visualizar ranking (direita);

Outra funcionalidade que pode ser habilitada é a de conquista de emblemas ou badges para os alunos (figura 4 a esquerda). Nesse caso, quando um aluno, por exemplo, acertar todas as perguntas de um questionário por duas vezes consecutivas, ele pode ganhar um badge como uma estrela de ouro. Será oferecido ao professor uma quantidade de badges pré-definidos. Esse é um dos princípios da gamificação, onde o jogador obtém status socialmente pelo seu esforço realizado. Outro objetivo do uso dos badges também pode ser para avisar o aluno de um certo comportamento de forma lúdica. Um dos emblemas pré-definidos é o do Entrevistador, e a sua descrição é: "Você ganhou um emblema do entrevistador! Será que você não anda falando muito em aula? ; $D$ ”. Dessa forma, o professor pode dar alguns feedbacks para os alunos de forma informal e divertida.
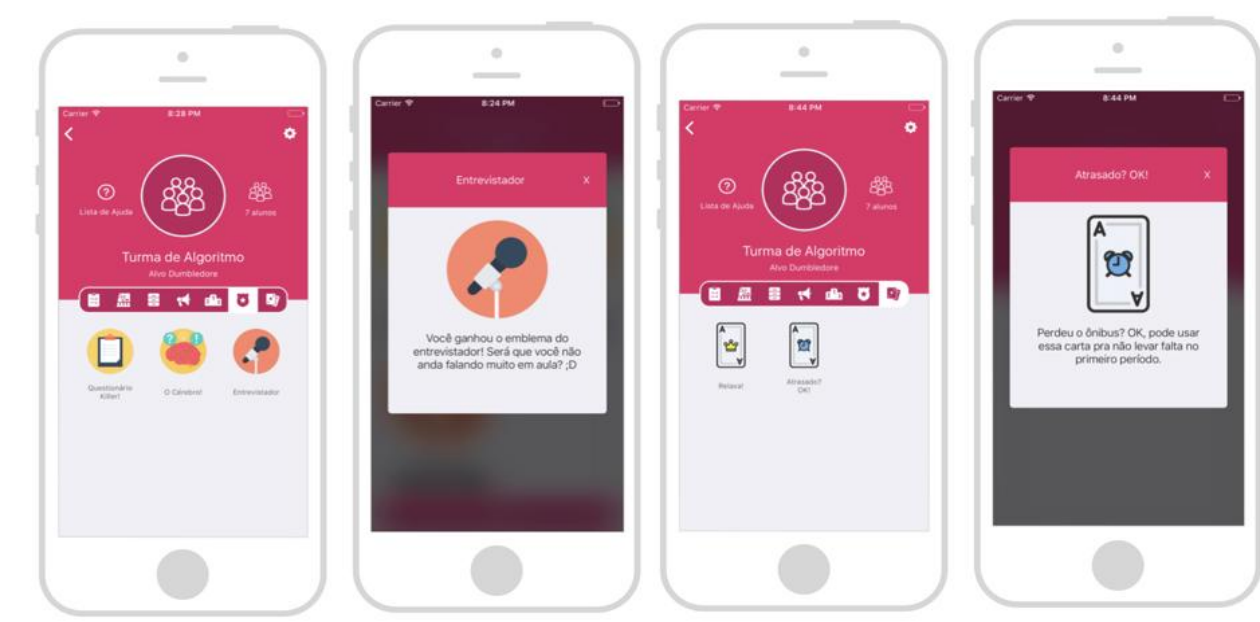

Figura 4. a) Interface para visualizar os badges (esquerda); b) visualizar o detalhe do badge (centro a esquerda); c) visualizar as cartas (centro a direita); d) visualizar o detalhe da carta (direita)

Além disso, um dos mecanismos da gamificação é a conquista ou achievement, quando se chega a um nível ou, no contexto da sala de aula, se realiza uma atividade 
extra. Será disponibilizada no aplicativo, conforme configuração do professor, a possibilidade de oferecer aos alunos conquista de cartas (figura 4 a direita). Essas cartas estarão no perfil do aluno até que ele a utilize. Um exemplo seria: o professor libera uma carta para quem realizar uma atividade extraclasse. Na carta, o aluno conquista a possibilidade de aumentar em um ponto a nota de um trabalho ou prova. $\mathrm{O}$ aluno deve escolher quando utilizar essa carta. Quando for utilizada, o professor deverá retirá-la do perfil do aluno, já que esta foi utilizada. Essa sensação de conquista está ligada também ao sentimento de propósito de se envolver em uma atividade, bem como de autonomia e tomada de decisão.

\section{Experiências piloto de aplicação em sala de aula}

A fim de analisar os potenciais do Colligo em cenários educacionais, realizou-se um projeto piloto com estudantes através de duas experimentações em sala de aula. Em se tratando do ambiente disponível para aplicação no Ensino Superior, participaram desse experimento 21 alunos da graduação e pós-graduação da Faculdade Senac Porto Alegre, numa faixa etária entre 18 e 30 anos.

A experimentação aconteceu no ambiente de sala de aula onde no ensino superior foi aplicada a uma disciplina de primeiro semestre do curso e na pós-graduação em uma disciplina de especialização do segundo módulo. Optou-se pela aplicação de um instrumento de coleta de dados em formato de questionário que seguiu as cinco métricas de Qualidade em Uso da ISO 25000 (SQuaRe) com perguntas quantitativas usando como métrica a escala Likert de cinco pontos. Dessa forma, foi avaliada a qualidade do produto em uso, ou seja, o quanto o produto, utilizado por usuários específicos, atende a necessidade para que atinjam metas específicas com eficácia, eficiência, satisfação, mitigação de risco e cobertura de contexto [ISO, 2008]. Além das questões de qualidade do aplicativo, foram realizadas também perguntas relativas aos possíveis impactos no processos de aprendizagem, na motivação e engajamento estimuladas pelo aplicativo em seu uso em sala de aula como apoio nas atividades pedagógicas.

Nas questões voltadas a avaliação das funcionalidades do projeto, foram realizadas perguntas sobre o grau de satisfação quanto ao uso dos itens: autenticação, questionários, presença, arquivos, notificações, ranking, emblemas e cartas. Mais de $85 \%$ dos entrevistados classificaram o seu grau de satisfação em "satisfeito" ou "muito satisfeito". Avaliando de modo geral os dados, pode-se ver que a maioria concorda plenamente com as funcionalidades e é interessante analisar que a maioria gostaria de utilizar o aplicativo em sala de aula.

Uma das perguntas que mais necessita atenção e possivelmente impacte nas próximas etapas do projeto é sobre o estímulo à participação em aula, uma das únicas questões que teve grau de discordância ou neutralidade de resposta correspondente a $15 \%$. Embora o grau de concordância seja alto, é importante fazer uma análise mais profunda do motivos de parte desses alunos não acreditarem que o Colligo os ajudaria a participar mais da aula. Uma observação feita por um dos alunos foi a falta de "anonimato para os alunos, pois temos que pensar que nem todos querem ser expostos". Pode-se, então, identificar uma questão a ser revista na abordagem atual pensando nesse tipo de aluno que se sente vigiado quando sabe que o professor pode identificar qual resposta o aluno selecionou. Futuramente, pode-se pensar em formas de trabalhar esse 
VI Congresso Brasileiro de Informática na Educação (CBIE 2017)

Anais do XXVIII Simpósio Brasileiro de Informática na Educação (SBIE 2017)

medo de exposição por parte do aluno no aplicativo. Sendo assim, dessa experimentação com alunos, foi possível identificar ações necessárias para melhoria do aplicativo.

Para complementar a experimentação, levou-se em consideração igualmente a opinião de docentes a respeito da utilização do aplicativo em sala de aula. Realizou-se uma avaliação junto a professores, onde um vídeo demonstrando todas as funcionalidades da aplicação foi enviado juntamente com um questionário a fim de identificar a aplicabilidade dessa ferramenta em sala de aula. No total, 12 professores de diversos níveis de ensino participaram, sendo $83 \%$ com 6 ou mais anos de experiência na área e desses apenas $25 \%$ utilizam técnicas de gamificação em suas aulas atualmente. Entre $80 \%$ e $91 \%$ dos entrevistados acredita que a aplicação auxilia a percepção dos professores quanto às dúvidas dos alunos, oferece recursos para estimular a proatividade e automotivação ao estudo por parte dos alunos e possibilita que o professor utilize técnicas de gamificação em sala de aula.

Assim como para os alunos, os professores poderiam avaliar a uso do das funcionalidades de autenticação, questionário, presença, arquivos, notificações, ranking, emblemas e cartas. O resultado foi bastante positivo, onde a maioria (cerca de $80 \%$ ) registrou que estava "satisfeito" ou "muito satisfeito" quanto às funcionalidades analisadas.

Observou-se que, diferente dos alunos, houve uma porcentagem maior de opiniões neutras quanto às funcionalidades. $O$ motivo pode ser a necessidade dos docentes de utilizar o aplicativo em sala de aula com suas turmas, para uma visão mais aprofundada do projeto. De qualquer forma, os professores se mostraram abertos a essa nova forma de interação em sala de aula e, através de suas respostas, é possível confirmar alguns dos objetivos específicos do projeto e das perspectivas teóricas que o fundamentaram.

A partir desta experimentação e validação com docentes, surgiram algumas sugestões para o futuro do aplicativo, como: apresentar um tutorial na primeira vez que o usuário entra no aplicativo, login social, integração com push notification, criação de cartas e emblemas pelo professor, possibilidade de avaliação do professor pelo aluno e alguma funcionalidade para aumentar a interatividade entre alunos.

\section{Considerações}

O perfil atual dos estudantes dos diversos níveis de educação se mostra pouco compatível com métodos tradicionais de ensino. $\mathrm{O}$ uso de mobile learning $\mathrm{e}$ gamificação dentro de práticas de metodologias ativas apresenta-se como um caminho interessante a seguir. Entretanto são poucos os recursos destinados a este fim que sejam adaptáveis a diversos públicos e lúdicos o bastante para captar a atenção dos envolvidos. Sendo assim, apresenta-se o Colligo como uma alternativa gratuita para aplicação de gamificação através de dispositivos móveis em sala de aula.

O aplicativo já tem sua versão em sistema operacional iOS e encontra-se em fase de implementação em sua versão Android $^{2}$, o que ampliará sua possibilidade de aplicação. A partir dessa expansão pretende-se realizar experimentações em outros níveis de ensino, tais como ensino médio e fundamental, para que se tenha dados de

\footnotetext{
${ }^{2}$ O desenvolvimento desta versão está prevista para ser finalizada até o final do ano de 2017
} 
VI Congresso Brasileiro de Informática na Educação (CBIE 2017)

Anais do XXVIII Simpósio Brasileiro de Informática na Educação (SBIE 2017)

aceitação e novas demandas específicas de públicos diferentes. Além disso, está previsto no futuro do projeto uma versão web que inicialmente será para professores a fim de facilitar a criação de conteúdo para uso no aplicativo.

\section{Referências}

Alves, L.; Minho, M.; Diniz, M. (2014) "Gamificação: diálogos com a educação". In Gamificação na educação. Ed. Pimenta Cultural. p. 300.

Domínguez, A., Navarrete, J. S., Marcos, L., Sanz, L. F., Pagés, C. and Herráiz, J. J. M. (2013) "Gamifying learning experiences: Practical implications and outcomes". In Journal Computers \& Education, p. 380-392.

França, R. M., Reategui, E. B. (2013) "SMILE-BR: aplicação de conceitos de gamificação em um ambiente de aprendizagem baseado em questionamento". In Anais do XXIV SBIE. Campinas - SP.

International Organization for Standardization - ISO. (2008) "ISO/IEC 25010 Software Engineering - Software Product Quality Requirements and Evaluation (SQuaRE): software and quality in use models". International Electrotechnical Commission. Geneva.

Kahoot!. (2017) "What is Kahhot?". https://kahoot.com/what-is-kahoot/.

Naismith, L., Lonsdale, P., Vavoula, G., \& Sharples, M. (2004). Literature Review in Mobile Technologies and Learning. FutureLab Report 11. https://www.nfer.ac.uk/publications/FUTL15/FUTL15.pdf

NearPod. (2017). "How it works?" https://nearpod.com/how-it-works.

Moura, A. (2010) "Apropriação do Telemóvel como Ferramenta de Mediação em Mobile Learning: Estudos de Caso em Contexto Educativo". Tese de Doutorado em Ciências da Educação. Instituto de Educação da Universidade do Minho.

Seol, S., Sharp, A., Kim, P. (2011) "Stanford Mobile Inquiry-based Learning Environment (SMILE): using mobile phones to promote student inquires in the elementary classroom". In Proceedings of IEEE World Congress in Computer Science, Computer Engineering, and Applied Computing.

Unesco. (2014) "Diretrizes de políticas para a aprendizagem móvel". http://unesdoc.unesco.org/images/0022/002277/227770por.pdf

Zichermann, G. and Cunningham, C. (2011) "Gamification by Design: Implementing Game Mechanics in Web and Mobile Apps". O’Reilly. 